\title{
Six months open label trial of leflunomide in active ankylosing spondylitis
}

\author{
H Haibel, M Rudwaleit, J Braun, J Sieper
}

Ann Rheum Dis 2005;64:124-126. doi: 10.1136/ard.2003.019174

Objective: To examine the potential therapeutic effects of leflunomide in patients with active AS in an open label study. Patients and methods: Twenty patients with AS fulfilling the 1984 modified New York criteria with a Bath AS Disease Activity Index (BASDAI) $>3$ were given leflunomide for 6 months. Clinical outcome assessments included disease activity (BASDAI), function (BASFI), metrology (BASMI), patient's and physician's global assessment, peripheral joint assessment, quality of life (SF-36), global pain, and CRP. Primary end point was a reduction of disease activity as measured by the BASDAI of $>25 \%$ at 6 months.

Results: A BASDAI 25\% improvement was noted in 5/20 $(25 \%)$ patients and a BASDAI $50 \%$ improvement in $4 / 20$ (20\%) patients. The absolute BASDAl did not change significantly over the 6 month study (4.9 at baseline $v 4.3$ at week 24, p>0.05). Similarly, no significant change was found for the BASFI, BASMI, patient's and physician's global assessment, SF-36 mental component, and CRP. For the 10 patients with peripheral arthritis, the mean number of inflamed joints was significantly reduced from 1.7 at baseline to 0.9 at week $12(p=0.034)$ and 0.2 at week 24 ( $p=0.039)$.

Conclusion: In this open study of patients with active AS only those with peripheral arthritis improved significantly with leflunomide treatment. Axial symptoms did not improve.

$\mathrm{T}$ reatment options for ankylosing spondylitis (AS), a rather common ${ }^{1}$ inflammatory rheumatic disease and prototype of the spondyloarthropathies starting mostly in the third decade of life, are limited. Currently, established treatment for AS consists of non-steroidal antirheumatic drugs (NSAIDs) and physical therapy. No established disease modifying antirheumatic drug (DMARD) treatment is available except for sulfasalazine, which seems to be effective in peripheral joint involvement ${ }^{2}$ and, possibly, for axial symptoms in patients with AS with shorter disease duration. ${ }^{3}$

Recently, tumour necrosis factor $\alpha$ blocking agents, both infliximab and etanercept, were shown to be highly effective in active AS resistant to NSAID treatment. ${ }^{4-7}$ However, because of their unknown long term side effects and high costs the number of patients with active AS treated with tumour necrosis factor $\alpha$ blockers will probably be limited.

Leflunomide is a relatively new DMARD and was shown to be highly effective and well tolerated in rheumatoid arthritis (RA). ${ }^{8}$ It inhibits de novo pyrimidine synthesis by selective inhibition of dihydro-orotate dehydrogenase, which is mainly used in $\mathrm{T}$ cells to synthesise pyrimidines.

This open label study aimed at investigating the efficacy and tolerability of leflunomide in the treatment of active AS over 6 months.

\section{PATIENTS AND METHODS}

In this open study we examined 20 patients (for characteristics see table 1) who fulfilled the 1984 modified New York criteria for AS and who did not respond sufficiently to NSAID treatment (defined as the highest tolerated dose of an NSAID for at least 4 weeks). To be enrolled, patients had to have active disease defined as a Bath Ankylosing Spondylitis Disease Activity Index (BASDAI) ${ }^{9} \geqslant 3$ on a numeric rating scale between 0 (no activity) and 10 (highest activity) as well as spinal pain $\geqslant 3$ on a similar rating scale (question 2 of the BASDAI questionnaire). DMARDs as well as steroids $>7.5 \mathrm{mg} /$ day were not allowed and had to be stopped at least 1 month before the start of treatment. Steroids $\leqslant 7.5 \mathrm{mg}$ had to remain stable for at least 1 month. Local ethics committee approval was obtained.

Exclusion criteria were pregnancy, any history of uncontrolled concomitant diseases, or clinical and laboratory examinations with abnormal and clinically relevant changes.

\section{Treatment protocol}

A starting dose of leflunomide $100 \mathrm{mg}$ daily was given for 3 days followed by leflunomide $20 \mathrm{mg} /$ day for 6 months, which has been proved to be effective and safe in the treatment of RA.

Clinical outcome assessments were performed every month and included the BASDAI, Bath Ankylosing Spondylitis Functional Index (BASFI), ${ }^{10}$ Bath Ankylosing Spondylitis Metrology Index (BASMI), ${ }^{11}$ patient's and physician's global assessment (numeric rating scales between 0 and 10 each), and quality of life (physical and mental health) (Short Form-36 (SF-36)). ${ }^{12}$ The primary outcome measure was a BASDAI improvement of $>25 \%$ after 6 months. Laboratory outcome assessments included the erythrocyte sedimentation rate and $\mathrm{C}$ reactive protein (CRP). NSAID treatment was continued, and reduced dosages were allowed but had to be recorded.

\section{Safety assessment}

At each visit blood pressure and heart rate were measured and patients were asked about side effects. Whole blood count, serum liver enzymes, and serum creatinine were investigated every other week.

\section{Statistics}

Statistics were performed as an intention to treat analysis as well as an analysis of the patients who completed the study. The non-parametric Wilcoxon signed rank test was used to

Abbreviations: AS, ankylosing spondylitis; BASDAl, Bath Ankylosing Spondylitis Disease Activity Index; BASFI, Bath Ankylosing Spondylitis Functional Index; BASMI, Bath Ankylosing Spondylitis Metrology Index; $\mathrm{CRP}, \mathrm{C}$ reactive protein; $\mathrm{DMARD}$, disease modifying antirheumatic drug; NSAID, non-steroidal anti-inflammatory drug; RA, rheumatoid arthritis; SF-36, Short Form-36; SSZ, sulfasalazine 


\section{Table 1 Patients' characteristics}

\begin{tabular}{ll}
\hline Number of patients & 20 \\
Male/female & $14 / 6$ \\
Age (years), mean (range) & $42(19-65)$ \\
Disease duration (years), mean (range) & $14(1-38)$ \\
BASDAl, mean (range) & $5.0(3.2-7.4)$ \\
HLA-B27 positive/negative & $17 / 3$ \\
CRP $>10 \mathrm{mg} /$ l & 11 \\
Peripheral joint involvement & 10 \\
History of uveitis & 5 \\
Enthesitis & 9 \\
Psoriasis & 7 \\
Psoriasis and peripheral arthritis & 4 \\
IBD & 0 \\
Spinal pain (BASDAl question 2) $>4$ & 17
\end{tabular}

Number of patients is shown unless indicated otherwise. BASDAI, Bath Ankylosing Spondylitis Disease Activity Index; CRP, $C$ reactive protein; IBD, inflammatory bowel disease,

compare changes between baseline and values after treatment. A value of $\mathrm{p}<0.05$ was considered significant.

\section{RESULTS}

Ten of 20 patients finished the study period of 6 months. Ten patients stopped treatment because of inefficacy, side effects, or loss of contact (table 2).

A BASDAI 25\% improvement, the primary outcome measure, was noted in $7 / 20(35 \%)$ patients after 3 months and in $5(25 \%)$ of the initial 20 patients after 6 months of treatment. A BASDAI 50\% improvement was seen in 5/20 $(25 \%)$ patients after 3 months and in $4(20 \%)$ of the initial 20 patients after 6 months.

There was no significant improvement of the BASDAI for the whole group of patients using an intention to treat analysis after 3 and after 6 months of treatment (mean 4.9 at baseline $v 4.6$ after 3 months, $\mathrm{p}=0.424$ and 4.3 after 6 months, $\mathrm{p}=0.221$ ) (fig $\mathrm{lA}$ ). Likewise, no significant change was found for the BASFI, BASMI, patient's and physician's global assessment, SF-36 mental component, and CRP.

\section{Peripheral arthritis and psoriasis}

In contrast with the general disease activity, peripheral arthritis improved significantly. The mean number of inflamed joints of the 10 patients with AS and with peripheral arthritis was significantly reduced to 0.9 at week $12(\mathrm{p}=0.034)$ and to 0.2 joints at week $24(\mathrm{p}=0.039)$ in comparison with 1.7 at baseline (fig 1B).

Again using an intention to treat analysis, there was a nonsignificant reduction of the BASDAI in the 10 patients with peripheral arthritis from 5.0 at baseline to 3.6 both at week 12 and week 24, whereas in the group without arthritis the BASDAI remained unchanged from 4.9 at baseline to 5.1 at week 12 and to 4.5 at week 24 (fig $1 \mathrm{~A}$ ).

The four patients who had a $50 \%$ improvement after 24 weeks all had either psoriasis or peripheral arthritis, or both, before the start of the study.

To date treatment is still continuing in the five patients with an improvement in the BASDAI of at least $25 \%$ after 24 weeks and remains effective for 22-24 months after the study end.

\section{Drop outs}

Side effects were common. Six patients stopped treatment because of side effects, five because of inefficacy and three of them because of both inefficacy and side effects (table 2). Of the 10 patients with peripheral arthritis, four dropped out between week 8 and 16 because of side effects in three patients or inefficacy in one patient.
Table 2 Reasons for withdrawal from the study

\begin{tabular}{lll}
\hline Reason for withdrawal & $\begin{array}{l}\text { Patients* } \\
\text { (n) }\end{array}$ & $\begin{array}{l}\text { Week of } \\
\text { withdrawal }\end{array}$ \\
\hline Inefficacy & 5 & \\
Side effects & 6 & 20 \\
Patient 1: systemic allergic skin reaction & & 16 \\
Patient 2: diarrhoea, nausea, hair loss, & 12 \\
impotence, tachycardia & 12 \\
Patient 3: skin allergy, diarrhoea & 02 \\
Patient 4: increase of liver enzymes & 08 \\
Patient 5: nausea, dizziness, dyspepsia & \\
Patient 6: diarrhoea, nausea, vomiting & \\
Non-compliance & 2 & \\
*Three patients had both inefficacy and side effects.
\end{tabular}

\section{DISCUSSION}

This open label study with 20 patients with NSAID resistant AS indicates that leflunomide is not effective for spinal symptoms but might be effective for peripheral arthritis.

Ten $(50 \%)$ of the 20 patients did not finish the study because of either inefficacy, side effects, or non-compliance (table 2). Leflunomide was effective in only 5 (25\%) patients, as judged by reaching the primary outcome measure of a $25 \%$ improvement in the BASDAI. However, this level of improvement would also be expected in a placebo group. In our recent randomised controlled trial with infliximab in patients with active $\mathrm{AS}^{4}{ }^{4} 34.3 \%$ of the placebo patients had a $25 \%$ improvement of their initial BASDAI. From NSAID studies it is also known that about $25 \%$ of the placebo patients can be regarded as responders. ${ }^{13}$

There was also no significant reduction of the mean BASDAI nor of other secondary outcome measures for axial symptoms.

Our results are very similar to previous experience with the treatment of AS with sulfasalazine (SSZ) in two multicentre,
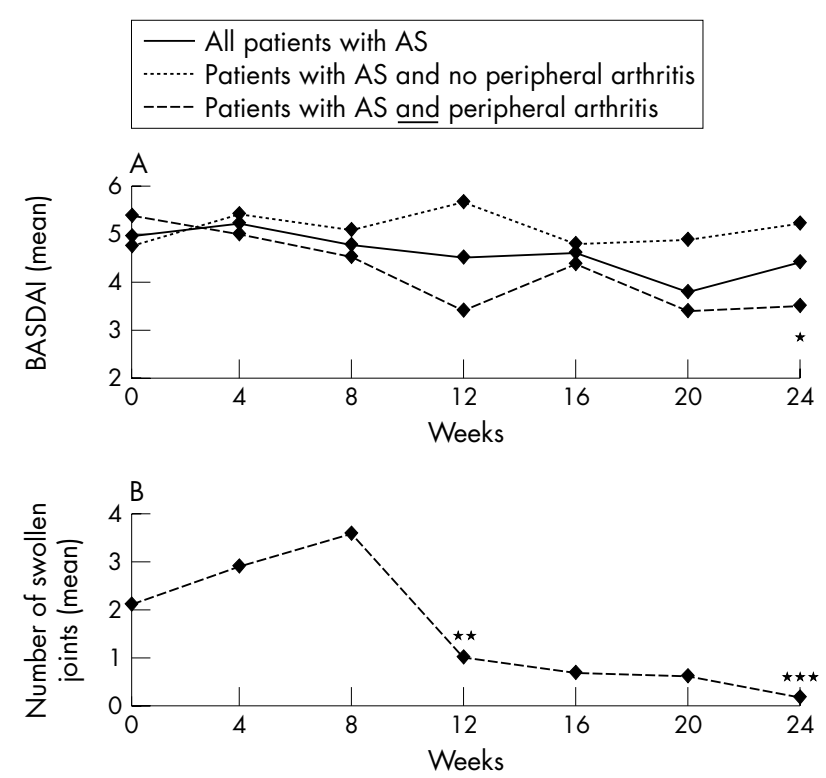

Figure 1 Response to treatment with leflunomide in 20 patients with AS. (A) BASDAl before, during, and after treatment with leflunomide over 24 weeks in all patients with AS, in 10 patients with AS without peripheral arthritis and 10 with peripheral arthritis. ${ }^{*} p>0.05$ versus baseline. (B) Number of swollen joints before, during, and after treatment with leflunomide over 24 weeks. ${ }^{* *} p=0.036$ week $12 v$ baseline; ${ }^{* * *} \mathrm{p}=0.016$ week $24 \mathrm{v}$ baseline. 
placebo controlled studies with patients with a comparable disease activity and disease duration ${ }^{2}{ }^{14}$ in which SSZ was no better than placebo.

However, in contrast with the lack of efficacy for spinal symptoms we could show that leflunomide had an effect on peripheral arthritis. Similar to treatment with SSZ the number of affected joints was significantly reduced in the 10 patients with peripheral joint manifestations. In four of the five patients who had an improvement of at least $25 \%$ of the initial BASDAI at the end of the study, an initial peripheral involvement was present, suggesting that improvement in the peripheral arthritis was mostly responsible for the improvement of the BASDAI. Three of these five patients also had psoriasis. In a multicentre, placebo controlled study with 190 patients with psoriatic arthritis treated with leflunomide or placebo a good efficacy of leflunomide versus placebo was recently shown. ${ }^{15}$ Whether leflunomide is mainly effective in psoriatic arthritis or any peripheral arthritis occurring in patients with AS has to be shown in future studies.

Compared with studies with leflunomide in $\mathrm{RA}^{,}{ }^{8}$ dropouts because of side effects, inefficacy, or non-compliance were little higher $(50 \%)$ than the expected range. In the RA studies $28-47 \%$ dropped out before the end of the study. However, the pattern of side effects was very similar (table 2). None of our patients reported a new onset of arterial hypertension, which was a difference from the studies in RA. This is possibly due to the differences in our study group, which consisted of younger patients in a better state of health.

In conclusion, our results indicate that leflunomide does not seem to improve the spinal symptoms of patients with AS but it might, similar to other DMARDs which are effective in the treatment of RA, be a new option for patients with spondyloarthropathy with peripheral arthritis. This has to be confirmed in larger studies concentrating on patients with peripheral arthritis.

\section{Authors' affiliations}

H Haibel, M Rudwaleit, J Sieper, Medical Department I, Rheumatology, Charité, Campus Benjamin Franklin Hospital, Berlin, Germany J Braun, Centre of Rheumatology Ruhrgebiet, Herne, Germany J Sieper, German Rheumatism Research Centre, Berlin, Germany

The topic of this paper forms part of Dr Haibel's thesis
Correspondence to: Ms H Haibel, Medical Department I, Rheumatology, Charité, Campus Benjamin Franklin, Hindenburgdamm 30, 12200 Berlin, Germany; haibel@zedat.fu-berlin.de

Accepted 16 March 2004

\section{REFERENCES}

1 Braun J, Bollow M, Remlinger G, Eggens U, Rudwaleit M, Distler A, et al. Prevalence of spondyloarthritides in HLA B27-positive and -negative blood donors. Arthritis Rheum 1998;41:58-67.

2 Dougados M, van der Linden S, Leirisalo-Repo M, Huitfeldt B, Juhlin R, Veys E, et al. Sulfasalazine in the treatment of spondyloarthritides. Arthritis Rheum 1995:38:618-27.

3 Nissila M, Lehtinen K, Leirisalo-Repo M, Luukkainen R, Mutru O, Yli-Kerttula U. Sulfasalazine in the treatment of ankylosing spondylitis. A twenty-six-week, placebo-controlled clinical trial. Arthritis Rheum 1988;31:1111-16.

4 Braun J, Brandt J, Listing J, Zink A, Alten R, Krause A, et al. Treatment of active ankylosing spondylitis with infliximab - a double-blind placebo controlled multicenter trial. Lancet 2002;359:1187-93.

5 Van Den Bosch F, Kruithof E, Baeten D, Herssens A, de Keyser F, Mielants H, et al. Randomized double-blind comparison of chimeric monoclonal antibody to tumor necrosis factor alpha (infliximab) versus placebo in active spondylarthropathy. Arthritis Rheum 2002;46:755-65.

6 Gorman JD, Sack KE, Davis JC Jr. Treatment of ankylosing spondylitis by inhibition of tumor necrosis factor alpha. N Engl J Med 2002;346:1349-56.

7 Brandt J, Kariouzov A, Listing J, Haibel H, Sörensen H, Grassnickel L, et al. Six months results of a German double-blind placebo controlled, phase-III clinical trial of etanercept in active ankylosing spondylitis. Arthritis Rheum 2003;48: 1667-75.

8 Smolen JS, Kalden JR, Scott DL, Rozman B, Kvien TK, Larsen A, et al. Efficacy and safety of leflunomide compared with placebo and sulfasalazine in active rheumatoid arthritis: a double-blind, randomised, multicentre trial. European Leflunomide Study Group. Lancet 1999;353:259-66.

9 Garrett S, Jenkinson T, Kennedy LG, Whitelock H, Gasford P, Calin A. A new approach to defining disease status in ankylosing spondylitis: the Bath Ankylosing Spondylitis Disease Activity Index. J Rheumatol 1994;21:2286-91.

10 Calin A, Garrett S, Whitelock HC, Kennedy LG, O'Hea J, Mallorie P, et al. A new approach to defining functional ability in ankylosing spondylitis. The Bath AS functional index. J Rheumatol 1994;21:2286-91.

11 Jenkinson TR, Mallorie PA, Whitelock HC, Kennedy LG, Garrett S, Calin A. Defining spinal mobility in ankylosing spondylitis. The Bath AS metrology index. J Rheumatol 1994;21:1694-8.

12 Medical Outcome Trust. How to score the SF-36 health survey, 2nd ed. Boston: Medical Outcome Trust, 1994.

13 Anderson JJ, Baron G, van der Heijde D, Felson DT, Dougados M. Ankylosing spondylitis assessment group preliminary definition of short-term improvement in ankylosing spondylitis. Arthritis Rheum 2001;44:1876-86.

14 Clegg DO, Reda DJ, Weisman MH, Blackburn WD, Cush JJ, Cannon GW, et al. Comparison of sulfasalazine and placebo in the treatment of ankylosing spondylitis. A Department of Veterans Affairs Cooperative Study. Arthritis Rheum 1996;39:2004-12

15 Kaltwasser J, Nash P, Gladman D, Rosen C, Behrens F, Mease P. Leflunomide in the treatment of psoriatic arthritis and psoriasis: data from a double-blind, randomized, placebo-controlled clinical trial [abstract]. Ann Rheum Dis 2003;62(suppl I):90. 